\title{
The Cost of Medicaid Savings: The Potential Detrimental Public Health Impact of Neonatal Circumcision Defunding
}

\author{
Annie L. Andrews, ${ }^{1}$ Gweneth B. Lazenby, ${ }^{2}$ Elizabeth Ramsey Unal, ${ }^{3}$ and Kit N. Simpson ${ }^{4}$ \\ ${ }^{1}$ Department of Pediatrics, Medical University of South Carolina, 135 Rutledge Avenue, P.O. Box 250561, \\ Charleston, SC 29425, USA \\ ${ }^{2}$ Department of Obstetrics and Gynecology, Medical University of South Carolina, Charleston, SC 29425, USA \\ ${ }^{3}$ Department of Obstetrics and Gynecology, Southern Illinois University School of Medicine, Springfield, IL 62794, USA \\ ${ }^{4}$ Department of Health Science and Research, Medical University of South Carolina, Charleston, SC 29425, USA
}

Correspondence should be addressed to Annie L. Andrews, andrewsan@musc.edu

Received 8 August 2012; Accepted 13 September 2012

Academic Editor: Gregory T. Spear

Copyright (C) 2012 Annie L. Andrews et al. This is an open access article distributed under the Creative Commons Attribution License, which permits unrestricted use, distribution, and reproduction in any medium, provided the original work is properly cited.

\begin{abstract}
Objective. To project the increased incidence of HIV and subsequent costs resulting from the expected decreased rate of circumcision due to Medicaid defunding in one southeastern state. Methods. Using 2009 South Carolina (SC) Medicaid birth cohort $(n=29,316)$, we calculated expected heterosexually acquired HIV cases at current circumcision rates. To calculate age/race/gender specific HIV incidence rates, we used 2009 South Carolina Department of Health and Environmental Control reported gender and race specific HIV cases, CDC reported age distribution of HIV cases, and 2009 S.C. population data. Accounting for current circumcision rates, we calculated the change in incidence of heterosexually acquired HIV assuming circumcision provides $60 \%$ protection against HIV transmission to males and $46 \%$ protection against male to female transmission. Published lifetime cost of HIV was used to calculate the cost of additional HIV cases. Results. Assuming Medicaid circumcision rates decrease from current nationally reported levels to zero secondary to defunding, we project an additional 55 male cases of HIV and 47 female cases of HIV among this birth cohort. The total cost discounted to time of infection of these additional HIV cases is $\$ 20,924,400$ for male cases and $\$ 17,711,400$ for female cases. The cost to circumcise males in this birth cohort at currently reported rates is $\$ 4,856,000$. Conclusions. For every year of decreased circumcision rates due to Medicaid defunding, we project over 100 additional HIV cases and $\$ 30,000,000$ in net medical costs.
\end{abstract}

\section{Introduction}

Eighteen state Medicaid programs have adopted policies that defund neonatal circumcision. Supporters of circumcision defunding have cited the original American Academy of Pediatrics statement on neonatal circumcision, which took a neutral stance on the subject stating "existing scientific evidence demonstrates potential medical benefits of newborn male circumcision; however, these data are not sufficient to recommend routine neonatal circumcision" [1]. However, in August 2012 the AAP released a revised statement stating "the health benefits of newborn male circumcision outweigh the risks and that the procedure's benefits justify access to this procedure for families who choose it." This significant change in the AAP's stance on the subject was in part prompted by three randomized controlled trials conducted in Africa which have shown that circumcision provides males with $60 \%$ protection against the heterosexual transmission of human immunodeficiency virus (HIV) [2-4]. The World Health Organization has endorsed circumcision as one method to reduce HIV transmission. Additionally, a recent study suggests that male circumcision may reduce male to female HIV transmission by $46 \%$ [5].

The results from these trials suggest that neonatal circumcision defunding may have broad implications. Since over $40 \%$ of all US births are funded by Medicaid [6], these polices have the potential for far-reaching effects. Medicaid defunding of neonatal circumcision will likely result in significantly lower rates of circumcision in the United States [7]. A reduction in rates of neonatal circumcision in states 
TABLE 1: Example calculation of age and race/ethnicity specific HIV incidence rates.

\begin{tabular}{lccccc}
\hline Age group & $\begin{array}{c}\text { Proportion of } \\
\text { cumulative black } \\
\text { male HIV/AIDs } \\
\text { cases by age group }\end{array}$ & $\begin{array}{c}\text { Number of black males } \\
\text { with new diagnoses of } \\
\text { HIV/AIDs in SC in } \\
2009^{\mathrm{b}}\end{array}$ & $\begin{array}{c}\text { Calculated number of } \\
\text { black male cases of } \\
\text { HIV/AIDs in SC in 2009 } \\
\text { by age group }\end{array}$ & $\begin{array}{c}\text { SC 2009 black male } \\
\text { population by age } \\
\text { group }\end{array}$ & $\begin{array}{c}\text { Calculated 2009 SC } \\
\text { black male HIV/AIDs } \\
\text { incidence rates by age } \\
\text { group }\end{array}$ \\
\hline $13-19$ & $3.4 \%$ & 418 & $.034 \times 418=14.2$ & 78,910 & $14.2 / 78,910=.018 \%$ \\
$20-29$ & $28.8 \%$ & 418 & $.288 \times 418=120.4$ & 104,604 & $120.4 / 104,604=.115 \%$ \\
$30-39$ & $35.3 \%$ & 418 & $.353 \times 418=147.6$ & 81,714 & $147.6 / 81,714=.181 \%$ \\
$40-49$ & $22.1 \%$ & 418 & $.221 \times 418=92.4$ & 85,557 & $92.4 / 85,557=.108 \%$ \\
\hline
\end{tabular}

${ }^{a}$ SC DHEC cumulative data from 1986 to 2009 reported that among black males with HIV/AIDs, 3.4\% were 13-19 years old, 28.8\% were 20-29 years old, and so forth.

bSC DHEC reported 418 black males with a new diagnosis of HIV/AIDs in 2009.

with defunding may result in an increased incidence of HIV infection. This increased incidence of HIV infection will result in additional medical costs that may offset the initial savings to Medicaid from circumcision defunding.

To ascertain the potential impact of circumcision defunding, we sought to determine the increased number of HIV cases expected in one southeastern state as a result of defunding, applying the circumcision prevention fraction (1relative risk) rates reported previously $[2-4,8]$. Additionally, we quantified the direct medical cost that would accrue as a result of these additional cases of HIV and compared this cost to the cost of circumcision.

We hypothesized that defunding of neonatal circumcision will lead to a substantial increased incidence of HIV infection and that the cost associated with these infections will offset the savings from defunding. If shown, these findings may serve as a model of the anticipated effects of decreased rates of neonatal circumcision for other states considering defunding.

South Carolina is one of the most recent states to defund neonatal circumcision and is ranked 10th among the 50 states and the District of Columbia in the 2008 annual rate of AIDS cases according to the CDC HIV/AIDS Surveillance Report [9]. According to the same report, South Carolina's two largest metropolitan areas, Columbia and Charleston, are ranked 7 th and 20th, respectively, among Metropolitan Statistical Areas in 2008 annual rates of AIDS cases [9]. In 2009 Medicaid covered 50.3\% of all births in South Carolina. We used South Carolina data for this analysis.

\section{Materials and Methods}

For this budget impact analysis, we developed a model from the perspective of the Medicaid program with the outcomes reported in terms of projected additional HIV cases and subsequent cost accrued. We began by calculating South Carolina HIV incidence rates (see, e.g., Table 1). We calculated race and gender specific HIV incidence rates using 2009 South Carolina Department of Health and Environmental Control (DHEC) HIV/AIDS cases reported by race and gender [10]. DHEC race/ethnicity is self-reported and is categorized as white, black, and "other." We then divided these cases into age categories (13-19 yrs, 20-29 yrs, 30-39yrs, and 40-49yrs) using cumulative HIV/AIDS data reported by South Carolina DHEC by age group, race, and gender. We used 2009 South Carolina population data (also reported by age group, race, and gender) to translate cases into incidence rates.

To determine the expected number of HIV cases in South Carolina for the 2009 Medicaid birth cohort at current circumcision levels, we then applied our calculated age group, race, and gender specific South Carolina HIV incidence rates to the 2009 South Carolina Medicaid birth cohort ( $n=29,316)$ as they aged through age 49 (see, e.g., Table 2). We limited our analysis to cases diagnosed through age 49 because the DHEC reported HIV/AIDS diagnoses by age group report age 50 and above as one age group, and we felt this was not specific enough for our analysis. Although there is a paucity of solid data in this age group, it is thought that relatively few cases are transmitted after age 50. While this exclusion may have led to an underestimation, given the uncertain data on HIV incidence in adults over age 50 this is the conservative approach. Starting at age 13 to avoid including vertically transmitted cases we calculated gender and race specific expected HIV cases for the cohort by year. Because the data on circumcision's prevention fraction for reducing HIV transmission is limited to heterosexually acquired HIV, we used Centers for Disease Control (CDC) statistics on HIV transmission category by gender and race to calculate the expected number of heterosexually acquired HIV cases for our cohort.

Assuming circumcision provides $60 \%$ protection against HIV transmission for males [2-4] and 46\% protection against male to female HIV transmission [8], and accounting for current reported circumcision rates by race, we calculated the additional number of HIV cases expected if Medicaid circumcision rates go from current rates to $0 \%$ as a result of Medicaid defunding (see, e.g., Tables 2 and 3). For current circumcision rates, we used race specific rates reported in 1999-2004 National Health and Nutrition Examination Survey [11]. For the "other" race group, we averaged the reported Mexican-American circumcision rate with the reported "other" race/ethnicity rate. Reported circumcision rates were $88 \%$ for whites, $73 \%$ for blacks, and $46 \%$ for other.

We then calculated the cost of the additional HIV cases by applying Schackman et al.'s published lifetime treatment cost discounted to the time of infection [12]. Their reported cost is $\$ 303,100$ in 2004 dollars. Inflated to 2010 dollars using 
TABLE 2: Example calculation of black male expected heterosexually acquired HIV cases and cost; SC 2009 Medicaid birth cohort.

\begin{tabular}{|c|c|c|c|c|c|}
\hline Cohort age & $\begin{array}{c}\text { Expected cases by } \\
\text { year at current } \\
\text { circumcision rates } \\
\text { (population }^{\mathrm{a}} \times \\
\text { age/gender/race } \\
\text { specific incidence } \\
\text { rate) }\end{array}$ & $\begin{array}{c}\text { Expected } \\
\text { heterosexually } \\
\text { acquired cases by year } \\
\text { (cases per year } \times \% \% \\
\text { heterosexually } \\
\text { acquired) }^{\mathrm{b}}\end{array}$ & $\begin{array}{l}\text { Total acquired cases by } \\
\text { year if no circumcision } \\
\text { (heterosexually acquired } \\
\text { cases by year } \times \\
\text { calculated factor) }^{c}\end{array}$ & $\begin{array}{l}\text { Additional acquired } \\
\text { cases expected if no } \\
\text { circumcision } \\
\text { (total cases-expected } \\
\text { cases) }\end{array}$ & $\begin{array}{l}\text { Lifetime HIV treatment } \\
\text { cost for additional cases } \\
\text { acquired per year } \\
\text { (discounted to time of } \\
\text { infection) })^{\mathrm{d}}\end{array}$ \\
\hline 13 & $6399 \times .00018=1.15$ & $1.15 \times .227=.26$ & $.26 \times 1.8=.47$ & $.47-.26=.21$ & $.21 \times \$ 377,360=\$ 78,978$ \\
\hline 14 & $6399 \times .00018=1.15$ & $1.15 \times .227=.26$ & $.26 \times 1.8=.47$ & $.47-.26=.21$ & $.21 \times \$ 377,360=\$ 78,978$ \\
\hline 15 & $6399 \times .00018=1.15$ & $1.15 \times .227=.26$ & $.26 \times 1.8=.47$ & $.47-.26=.21$ & $.21 \times \$ 377,360=\$ 78,978$ \\
\hline
\end{tabular}

a 2009 SC medicaid birth cohort-black male population.

${ }^{\mathrm{b}} \mathrm{CDC}$ HIV surveillance report statistics on diagnosis of HIV infection by race/ethnicity, gender, and transmission category (22.7\% of black male HIV infections were reported as heterosexually transmitted).

${ }^{\mathrm{c}}$ See Table 3 for explanation of factor calculation.

dUsing Schackman et al's discounted lifetime HIV treatment cost of \$303,100 (in \$US2004) inflated to \$US2010 for a lifetime treatment cost of \$377,360 per case.

TABLe 3: Explanation of calculated increased race/gender specific HIV rates.

\begin{tabular}{|c|c|c|c|c|c|}
\hline Race/gender & $\begin{array}{l}\text { Current } \\
\text { circumcision rate }^{\mathrm{a}}\end{array}$ & $\begin{array}{l}\text { Expected HIV cases due to } \\
\text { heterosexual contact at } \\
\text { current circumcision rates }\end{array}$ & $\begin{array}{l}\text { Additional expected HIV } \\
\text { cases due to heterosexual } \\
\text { contact if circumcision } \\
\text { rates drop to zero }\end{array}$ & $\begin{array}{l}\text { Total expected HIV cases due to } \\
\text { heterosexual contact if } \\
\text { circumcision rates drop to zero }\end{array}$ & $\begin{array}{l}\text { Calculated } \\
\text { factor }^{\mathrm{c}}\end{array}$ \\
\hline Black male & $73 \%$ & 60.5 & 47.1 & 107.6 & 1.8 \\
\hline White male & $88 \%$ & 1.8 & 2.0 & 3.8 & 2.1 \\
\hline Other male & $46 \%$ & 12.8 & 4.9 & 17.7 & 1.4 \\
\hline Black female & $73 \%$ & 69.5 & 35.1 & 104.6 & 1.5 \\
\hline White female & $88 \%$ & 7.0 & 4.8 & 11.8 & 1.7 \\
\hline Other female & $46 \%$ & 24.4 & 6.5 & 30.9 & 1.3 \\
\hline
\end{tabular}

${ }^{a}$ As reported in 1999-2004 national health and nutrition examination survey. We applied the race specific male circumcision rate to the concordant race females.

${ }^{b}$ See Table 2 for explanation of calculation of expected HIV cases at current circumcision rates.

${ }^{\mathrm{c}}$ The relationship between expected cases (at current circumcision rates) and the total number of cases that would be observed in the absence of any circumcision is: Expected cases $=$ Total cases $(1-$ rate $)+$ Total cases $*$ rate $*(1-$ eff $)$, where "rate" is the proportion of individuals in the population who are circumcised and "eff" is effectiveness- that is, the amount by which circumcision reduces disease transmission. Total cases - expected cases is the number of additional cases that would be added in the absence of circumcision. The calculated factor is total cases/expected cases.

medical cost specific consumer price index (CPI) we used a lifetime treatment cost of $\$ 377,360$ for each additional HIV case projected. Using this value, we then tabulated total cumulative costs for the additional HIV cases. We then further discounted the treatment costs back to the time of birth to allow an additional direct comparison to Medicaid savings from circumcision defunding during the cohort's birth year.

We also calculated the cost to circumcise all males in the birth cohort at currently reported circumcision rates. We used the 2008 national median reported cost of neonatal circumcision of $\$ 339$ inflated to 2010 dollars using the medical cost specific CPI to yield a cost per circumcision of $\$ 442$ [13].

For the sensitivity analysis, we used the average of lower and upper bounds of the confidence intervals from the perprotocol analyses of the randomized controlled trials to vary the prevention fraction of circumcision for reducing male HIV transmission from $39 \%$ to $80 \%$, a method previously published in the literature $[2-4,14]$. Additionally using the confidence interval limits reported by Hallett et al. we varied the prevention fraction of circumcision for reducing male to female transmission from $4 \%$ to $69 \%$ [8]. We also calculated the lower limit of annual HIV cost that would result in circumcision no longer being cost saving.

To account for the possibility that some parents will choose to pay out of pocket for neonatal circumcision, we varied the total number of additional cases and total additional cost attributed to the increased HIV rates. We calculated additional cases and cost if 25\%, 50\%, and 75\% of parents pay out of pocket for circumcision.

\section{Results}

Assuming circumcision provides $60 \%$ protection against HIV transmission to males and $46 \%$ protection against transmission to females, and if the circumcision rates in this 2009 birth cohort decrease to $0 \%$ as a result of 
TABLE 4: Projected additional male cases of HIV and additional direct medical costs ${ }^{\mathrm{a}}$.

\begin{tabular}{|c|c|c|c|c|}
\hline & $\begin{array}{c}\text { African } \\
\text { American } \\
n=6399\end{array}$ & $\begin{array}{c}\text { White } \\
n=5776\end{array}$ & $\begin{array}{c}\text { Other } \\
n=2680\end{array}$ & $\begin{array}{c}\text { Total } \\
n=14,855\end{array}$ \\
\hline \multicolumn{5}{|c|}{ Baseline prevention fraction $(60 \%)^{\mathrm{b}}$} \\
\hline Additional HIV cases & 48 & 2 & 5 & 55 \\
\hline Additional cost discounted to time of infection ${ }^{c}$ & $\$ 18,252,700$ & $\$ 739,100$ & $\$ 1,932,600$ & $\$ 20,924,400$ \\
\hline Additional cost discounted to birth ${ }^{\mathrm{d}}$ & $\$ 7,150,000$ & $\$ 294,600$ & $\$ 804,200$ & $\$ 8,248,800$ \\
\hline \multicolumn{5}{|c|}{ Highest prevention fraction $(80 \%)^{\mathrm{b}}$} \\
\hline Additional HIV cases & 85 & 4 & 8 & 97 \\
\hline Additional cost discounted to time of infection ${ }^{c}$ & $\$ 31,942,200$ & $\$ 1,612,600$ & $\$ 2,989,000$ & $\$ 36,543,800$ \\
\hline Additional cost discounted to birth ${ }^{\mathrm{d}}$ & $\$ 12,512,400$ & $\$ 642,700$ & $\$ 1,206,300$ & $\$ 14,361,400$ \\
\hline \multicolumn{5}{|c|}{ Lowest prevention fraction $(39 \%)^{\mathrm{b}}$} \\
\hline Additional HIV cases & 24 & 1 & 3 & 28 \\
\hline Additional cost discounted to time of infection ${ }^{c}$ & $\$ 9,126,300$ & $\$ 336,000$ & $\$ 966,300$ & $\$ 10,428,600$ \\
\hline Additional cost discounted to birth ${ }^{\mathrm{d}}$ & $\$ 3,575,000$ & $\$ 133,900$ & $\$ 402,100$ & $\$ 4,111,000$ \\
\hline
\end{tabular}

Medicaid defunding of neonatal circumcision, we estimate an additional 55 projected male cases of HIV and 47 female cases of HIV in this Medicaid birth year cohort. Using the 2009 reported cases of HIV/AIDS in South Carolina, this figure represents a $13 \%$ increase in annual incidence if no future Medicaid cohorts are circumcised. We project the total cost of these cases in 2010 dollars is $\$ 38,635,800$ discounted to time of infection and $\$ 15,540,800$ discounted to birth year. These figures account for lifetime treatment costs for the 2009 birth cohort (Tables 4 and 5).

The cost to circumcise males in the 2009 Medicaid birth cohort in 2010 dollars at current reported circumcision rates is $\$ 4,856,200$. Therefore, assuming baseline circumcision prevention fraction of HIV transmission of $60 \%$ for males and $46 \%$ for females, for every year that Medicaid does not fund neonatal circumcision, there will be an initial $\$ 4,856,200$ cost savings but we project $\$ 38,635,800$ in medical cost (discounted to time of infection) related to increased HIV infection rates. Further discounting to birth year, the total cost of the additional HIV infections is $\$ 15,635,800$, resulting in a net cost of $\$ 10,684,600$ for each year of Medicaid births.

If the prevention fraction of circumcision for reducing male HIV transmission is $39 \%$ and the prevention fraction for reducing male to female transmission is lowered to $4 \%$, the projected number of additional HIV cases in males is 28 and in females is 2.8 . This represents a $4 \%$ increase in annual HIV incidence if no future Medicaid cohorts are circumcised. We project the total cost of these cases in 2010 dollars is $\$ 11,504,400$ discounted to time of infection and $\$ 4,554,300$ discounted to birth year. Therefore, assuming the lowest reported efficacy for both males and females and discounting to birth year, defunding neonatal circumcision results in a net savings of $\$ 301,900$ per birth year cohort (Tables 4 and 5).
If the prevention fraction of circumcision for reducing male HIV transmission is $80 \%$ rather than $60 \%$ and the prevention fraction for reducing male to female transmission is $69 \%$ rather than $46 \%$, the projected number of additional HIV cases in males is 97 and in females is 112. This represents a $27 \%$ increase in annual HIV incidence if no future Medicaid cohorts are circumcised. We project the total cost of these cases in 2010 dollars is $\$ 79,178,100$ discounted to time of infection and $\$ 31,847,300$ discounted to birth year. Therefore, assuming the highest reported efficacy for both males and females and discounting to birth year, defunding neonatal circumcision would result in a net cost of $\$ 26,991,100$ per birth year cohort (Tables 4 and 5).

Assuming the baseline prevention fractions, if the lifetime treatment cost of HIV infection discounted to time of birth was as low as $\$ 47,600$, circumcision would no longer be costsaving. Our results also show that if you combine the lowest estimates of circumcision prevention fraction for males and females (39\% and 4\%, resp.), the costsavings disappear by a margin of $\$ 301,900$.

We recognize that a proportion of parents will elect to pay out of pocket for neonatal circumcision. If $25 \%$ of parents who would have elected neonatal circumcision chose to pay for this procedure, we expect to see an additional 76 cases of HIV with an additional cost of $\$ 11,655,600$ (discounted to birth year), yielding a net cost per birth year cohort $\$ 6,799,400$. If $50 \%$ of parents pay out of pocket, we project an additional 52 cases of HIV with an additional cost of $\$ 7,770,400$ (discounted to birth year), yielding a net cost per birth year cohort of $\$ 2,914,200$. If $75 \%$ of parents pay out of pocket, we expect 26 additional HIV cases with an additional cost of $\$ 3,885,200$ (discounted to birth year) yielding a net savings per birth year cohort of $\$ 971,000$ ) (Table 6). See Table 7 for summary of expected HIV cases with and without circumcision funding. 
TABLe 5: Projected additional female cases of HIV and additional direct medical costs ${ }^{\mathrm{a}}$.

\begin{tabular}{|c|c|c|c|c|}
\hline & $\begin{array}{c}\text { African } \\
\text { American } \\
n=6379\end{array}$ & $\begin{array}{l}\text { White } \\
n=5620\end{array}$ & $\begin{array}{l}\text { Other } \\
n=2462\end{array}$ & $\begin{array}{c}\text { Total } \\
n=14,461\end{array}$ \\
\hline \multicolumn{5}{|c|}{ Baseline prevention fraction $(46 \%)^{\mathrm{b}}$} \\
\hline Additional HIV cases & 35 & 5 & 7 & 47 \\
\hline $\begin{array}{l}\text { Additional cost discounted to time of } \\
\text { infection }^{c}\end{array}$ & $\$ 13,113,500$ & $\$ 1,839,700$ & $\$ 2,758,200$ & $\$ 17,711,400$ \\
\hline Additional cost discounted to birth ${ }^{\mathrm{d}}$ & $\$ 5,316,900$ & $\$ 777,200$ & $\$ 1,197,900$ & $\$ 7,292,000$ \\
\hline \multicolumn{5}{|c|}{ Highest prevention fraction $(69 \%)^{b}$} \\
\hline Additional HIV cases & 90 & 10 & 12 & 112 \\
\hline $\begin{array}{l}\text { Additional cost discounted to time of } \\
\text { infection }^{c}\end{array}$ & $\$ 34,095,100$ & $\$ 3,942,200$ & $\$ 4,597,000$ & $\$ 42,634,300$ \\
\hline Additional cost discounted to birth ${ }^{\mathrm{d}}$ & $\$ 13,824,000$ & $\$ 1,665,400$ & $\$ 1,996,500$ & $\$ 17,485,900$ \\
\hline \multicolumn{5}{|c|}{ Lowest prevention fraction $(4 \%)^{\mathrm{b}}$} \\
\hline Additional HIV cases & 2 & .3 & .5 & 2.8 \\
\hline $\begin{array}{l}\text { Additional cost discounted to time of } \\
\text { infection }^{c}\end{array}$ & $\$ 786,800$ & $\$ 105,100$ & $\$ 183,900$ & $\$ 1,075,800$ \\
\hline Additional cost discounted to birth ${ }^{\mathrm{d}}$ & $\$ 319,000$ & $\$ 44,400$ & $\$ 79,900$ & $\$ 443,300$ \\
\hline
\end{tabular}

TABLE 6: Projected additional cases of HIV and additional direct medical costs by percentage of parents electing to pay out of pocket for circumcision $^{\mathrm{a}}$.

\begin{tabular}{lcccc}
\hline & $\begin{array}{c}\text { Additional male HIV } \\
\text { cases } \\
(n=14,855)\end{array}$ & $\begin{array}{c}\text { Additional female } \\
\text { HIV cases } \\
(n=14,461)\end{array}$ & $\begin{array}{c}\text { Total male and female } \\
\text { discounted costs }\end{array}$ & $\begin{array}{c}\text { Net cost per birth year } \\
\text { cohort }\end{array}$ \\
\hline $25 \%$ pay out-of-pocket & 41 & 35 & $\$ 11,655,600$ & $\$ 6,799,400$ \\
$50 \%$ pay out-of-pocket & 28 & 24 & $\$ 7,770,400$ & $\$ 2,914,200$ \\
$75 \%$ pay out-of-pocket & 14 & 12 & $\$ 3,885,200$ & $\$-971,000$ \\
\hline
\end{tabular}

${ }^{a}$ Per South Carolina Medicaid birth year cohort. Assuming baseline prevention fraction (60\% for males and $46 \%$ for females) of circumcision at reducing HIV transmission.

${ }^{\mathrm{b}}$ Costs discounted by $3 \%$ from cohort birth year.

TABLE 7: Expected heterosexually acquired HIV cases in South Carolina for the 2009 medicaid birth cohort aged through age 49 with and without circumcision funding.

\begin{tabular}{lcc}
\hline & $\begin{array}{c}\text { Expected HIV cases with } \\
\text { circumcision funding }\end{array}$ & $\begin{array}{c}\text { Expected HIV cases } \\
\text { without circumcision } \\
\text { funding }\end{array}$ \\
\hline Black male & 60 & 109 \\
Black female & 70 & 104 \\
White male & 2 & 4 \\
White female & 7 & 12 \\
Other male & 13 & 18 \\
Other female & 24 & 32 \\
\hline
\end{tabular}

${ }^{a}$ Assuming baseline prevention fractions.

\section{Discussion}

This analysis demonstrates that any cost savings expected as a result of circumcision defunding will be offset by the direct medical cost incurred from an increased number of HIV cases within the population. For each year of Medicaid births that goes uncircumcised, there will be an expected $\$ 38,635,800$ of HIV-related medical costs accrued. Therefore, considering the $\$ 4,856,200$ cost to circumcise males in each Medicaid birth cohort at currently reported levels, a net cost of $\$ 33,779,600$ (discounted to time of infection) or $\$ 10,684,600$ (discounted to birth) per Medicaid birth cohort year is projected.

This analysis only accounted for heterosexually acquired HIV given that the randomized controlled trials only studied 
heterosexual men [2-4]. There is currently little evidence to suggest that male circumcision has a significant impact on the transmission of HIV among men who have sex with men [15]. We also did not consider the increased rates of herpes simplex virus type-2 (HSV-2) and human papilloma virus (HPV) that would be expected if circumcision rates decline [16]. Uncircumcised men are at significantly increased risk of acquiring both of these infections [16]. A $28-34 \%$ reduction in HSV-2 acquisition and a $32-35 \%$ reduction in HPV acquisition have been shown in circumcised men [16, 17]. Additionally, male circumcision reduces the incidence of bacterial vaginosis (BV), Trichomonas, and HPV in female partners [17-19]. The expected increased incidence of HSV-2, HPV, bacterial vaginosis, Trichomonas infections and cervical cancer broadens the public health impact of decreased circumcision rates. These additional infections will contribute to the rising medical costs related to decreased circumcision rates. Therefore, our analysis represents a conservative estimate of the expected public health implications of Medicaid defunding of neonatal circumcision.

Accounting for current South Carolina race/gender/ transmission category HIV incidence rates, the majority of the effect of increased incidence of HIV as a result of decreased neonatal circumcision rates is seen in the black male population. They represent $47 \%$ of the additional HIV cases projected using the baseline estimates of circumcision's protective effect. Additionally, in 2009 Medicaid covered $67.4 \%$ of all black births in South Carolina, while only covering $36.9 \%$ of all white births. The lack of coverage for neonatal circumcision will deprive this minority population of the health benefits of decreased rates of HIV, HSV, HPV, and other infections. Additionally, the sexual partners of these men, more likely to be minorities, will have a disproportionate risk of HIV infection. Consequently, Medicaid defunding of neonatal circumcision may contribute to future health disparities.

Recently, Kacker et al. published a Markov model projecting increased prevalence of HIV, HPV, HSV-2, infant UTI, BV, trichomoniasis as a result of decreased rates of male circumcision [20]. They reported the net expenditure per annual birth cohort to increase by $\$ 505$ million if circumcision rates fall to $10 \%$. Our findings are consistent with this, but focused on only increased costs related to increased HIV incidence and specific to the South Carolina Medicaid population. This provides an example of a conservative estimate of the budget impact each state Medicaid program could expect if neonatal circumcision is defunded.

There are several limitations to this study. We applied prevention fractions from African randomized controlled trials to a US population. While there are inherent differences between these populations, there is no reason to believe circumcision would have radically different effects in different populations as findings from prospective studies in the US are consistent with the results from the African trials [11,2123]. Additionally, we assumed the age, gender, and race specific baseline HIV incidence rates would be unchanged from present day until the cohort reaches age 49 . We consider this a conservative assumption given that for every year of decreased circumcision rates, there is expected to be an increased baseline incidence of HIV. However it is also likely that there will be additional HIV prevention strategies over this time period that would reduce incidence and thereby effect costs accrued. Our methodology assumes a linear relationship between circumcision rates and the number of HIV cases. This does not take into account the fact that as transmission efficiency increases, each index case causes additional secondary cases, which cause tertiary cases, and so on. This makes our findings conservative as it leads to an underestimation of the total effect. Also, we did not include any cases acquired after age 49. Although the NHANES report of current circumcision rates is considered an accurate estimate, it is difficult to document the true prevalence of male circumcision. We also assumed that decreased rates of circumcision among male Medicaid recipients would directly translate to effects on concordant race female Medicaid recipients. We were forced to use national data from the CDC on HIV transmission rates and apply it to state data. This analysis did not take into account the cost of any possible circumcision-related complications. However, significant complications from neonatal circumcision are rare and we feel the estimated cost of such complications would be modest in comparison to the HIV-related cost [24]. The available data on circumcision's effect on male to female HIV transmission is limited to observational studies and is therefore not as strong as the randomized controlled trial data informing the female to male transmission rates. We have examined circumcision as one of many potential public health interventions to decrease HIV transmission rates. While we are unable to truly predict what will happen over 62 years, decision analysis models take the best current evidence and reasonable assumptions to inform decisions that must be made today. The effect of the model assumptions on the projected outcomes are carefully tested by sensitivity analysis.

\section{Conclusion}

These findings suggest a need to reconsider fiscal policy decisions surrounding neonatal circumcision, as their public health impact may be much broader than originally thought. In the meantime we feel it is critical for physicians to recognize the potential health benefits of male circumcision and use this information to deliver effective education and counseling to expectant parents. Future research directions include further cost-effectiveness analyses to quantify the other potential public health consequences of neonatal circumcision defunding.

\section{Conflict of Interests}

The authors have no conflict of interests relevant to this paper to disclose.

\section{Acknowledgment}

This paper was supported by National Research Service Award (HRSA T32HP10255). 


\section{References}

[1] C. M. Lannon, A. G. D. Bailey, A. R. Fleischman et al., "Circumcision policy statement," Pediatrics, vol. 103, no. 3, pp. 686-693, 1999.

[2] R. H. Gray, G. Kigozi, D. Serwadda et al., "Male circumcision for HIV prevention in men in Rakai, Uganda: a randomised trial," The Lancet, vol. 369, no. 9562, pp. 657-666, 2007.

[3] R. C. Bailey, S. Moses, C. B. Parker et al., "Male circumcision for HIV prevention in young men in Kisumu, Kenya: a randomised controlled trial," The Lancet, vol. 369, no. 9562, pp. 643-656, 2007.

[4] B. Auvert, D. Taljaard, E. Lagarde, J. Sobngwi-Tambekou, R. Sitta, and A. Puren, "Randomized, controlled intervention trial of male circumcision for reduction of HIV infection risk: the ANRS 1265 trial," PLoS Medicine, vol. 2, no. 11, article e298, pp. 1112-1122, 2005.

[5] T. B. Hallett, R. A. Alsallaq, J. M. Baeten et al., "Will circumcision provide even more protection from HIV to women and men? New estimates of the population impact of circumcision interventions," Sexually Transmitted Infections, vol. 87, no. 2, pp. 88-93, 2011.

[6] Association NG, Medicaid Births as a Percentage of Total Births, 2002 and 2003, National Governors Association, 2007.

[7] A. A. Leibowitz, K. Desmond, and T. Belin, "Determinants and policy implications of male circumcision in the United States," American Journal of Public Health, vol. 99, no. 1, pp. 138-145, 2009.

[8] T. B. Hallett, R. A. Alsallaq, J. M. Baeten et al., "Will circumcision provide even more protection from HIV to women and men? New estimates of the population impact of circumcision interventions," Sexually Transmitted Infections, vol. 87, no. 2, pp. 88-93, 2011.

[9] (U.S.) CfDC, $2008 \mathrm{http://www.cdc.gov/hiv/surveillance/}$ resources/reports/2008report/table20.htm.

[10] http://www.scdhec.gov/health/disease/sts/index.htm.

[11] F. Xu, L. E. Markowitz, M. R. Sternberg, and S. O. Aral, "Prevalence of circumcision and herpes simplex virus type 2 infection in men in the United States: the National Health and Nutrition Examination Survey (NHANES), 1999-2004," Sexually Transmitted Diseases, vol. 34, no. 7, pp. 479-484, 2007.

[12] B. R. Schackman, K. A. Gebo, R. P. Walensky et al., "The lifetime cost of current human immunodeficiency virus care in the United States," Medical Care, vol. 44, no. 11, pp. 990997, 2006.

[13] Practice Management Information Corporation (PMIC), MedicalFees in the United States 2008, PMIC, Los Angeles, Calif, USA, 2008.

[14] S. L. Sansom, V. S. Prabhu, A. B. Hutchinson et al., "Costeffectiveness of newborn circumcision in reducing lifetime HIV risk among U.S. males," PLoS ONE, vol. 5, no. 1, Article ID e8723, 2010

[15] G. A. Millett, S. A. Flores, G. Marks, J. B. Reed, and J. H. Herbst, "Circumcision status and risk of HIV and sexually transmitted infections among men who have sex with men: a meta-analysis," Journal of the American Medical Association, vol. 300, no. 14, pp. 1674-1684, 2008.

[16] A. A. R. Tobian, D. Serwadda, T. C. Quinn et al., "Male circumcision for the prevention of HSV-2 and HPV infections and syphilis," New England Journal of Medicine, vol. 360, no. 13, pp. 1298-1309, 2009.

[17] A. A. R. Tobian, R. H. Gray, and T. C. Quinn, "Male circumcision for the prevention of acquisition and transmission of sexually transmitted infections: the case for neonatal circumcision," Archives of Pediatrics and Adolescent Medicine, vol. 164, no. 1, pp. 78-84, 2010.

[18] R. H. Gray, G. Kigozi, D. Serwadda et al., "The effects of male circumcision on female partners' genital tract symptoms and vaginal infections in a randomized trial in Rakai, Uganda," American Journal of Obstetrics and Gynecology, vol. 200, no. 1, pp. 42.e41-42.e47, 2009.

[19] M. J. Wawer, A. A. Tobian, G. Kigozi et al., "Effect of circumcision of HIV-negative men on transmission of human papillomavirus to HIV-negative women: a randomised trial in Rakai, Uganda," The Lancet, vol. 377, no. 9761, pp. 209-218, 2011.

[20] S. Kacker, K. D. Frick, C. A. Gaydos, and A. A. Tobian, "Costs and effectiveness of neonatal male circumcision," Archives of Pediatrics \& Adolescent Medicine, vol. 166, no. 10, pp. 1-9, 2012.

[21] E. E. Telzak, M. A. Chiasson, P. J. Bevier, R. L. Stoneburner, K. G. Castro, and H. W. Jaffe, "HIV-1 seroconversion in patients with and without genital ulcer disease: a prospective study," Annals of Internal Medicine, vol. 119, no. 12, pp. 1181-1186, 1993.

[22] L. Warner, K. G. Ghanem, D. R. Newman, M. Macaluso, P. S. Sullivan, and E. J. Erbelding, "Male circumcision and risk of HIV infection among heterosexual African American men attending Baltimore sexually transmitted disease clinics," Journal of Infectious Diseases, vol. 199, no. 1, pp. 59-65, 2009.

[23] P. S. Sullivan, P. H. Kilmarx, T. A. Peterman et al., "Male circumcision for prevention of HIV transmission: what the new data mean for HIV prevention in the United States," PLoS Medicine, vol. 4, no. 7, article e223, pp. 1162-1166, 2007.

[24] H. A. Weiss, N. Larke, D. Halperin, and I. Schenker, "Complications of circumcision in male neonates, infants and children: a systematic review," BMC Urology, vol. 10, article 2, 2010. 


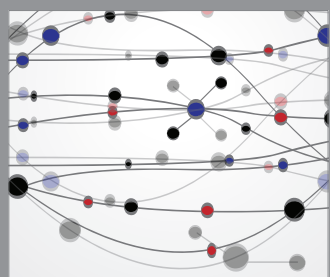

The Scientific World Journal
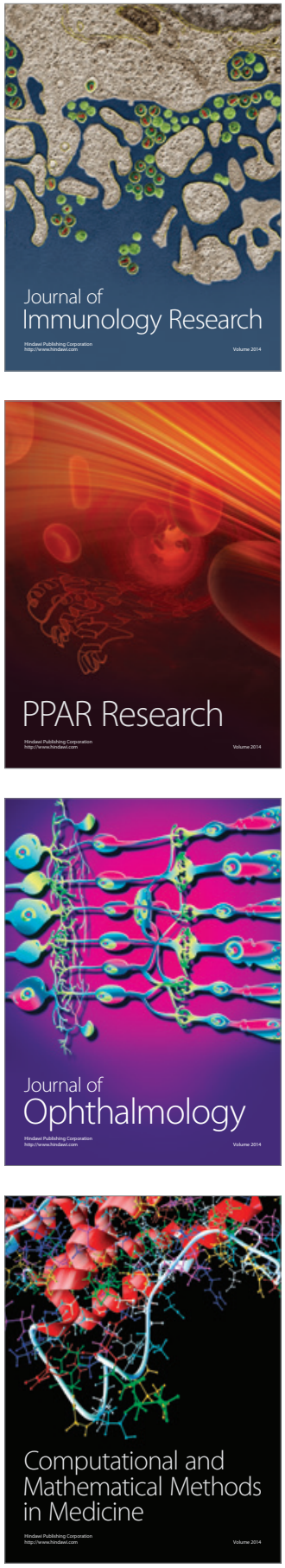

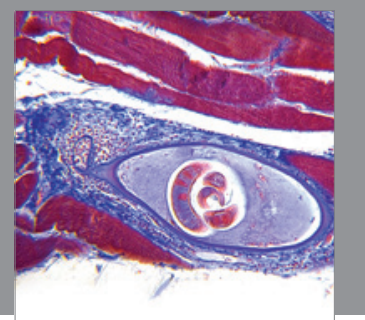

Gastroenterology

Research and Practice
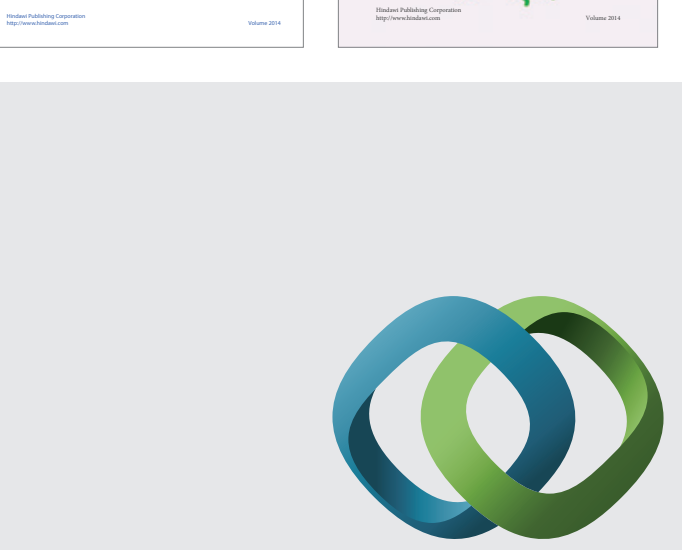

\section{Hindawi}

Submit your manuscripts at

http://www.hindawi.com
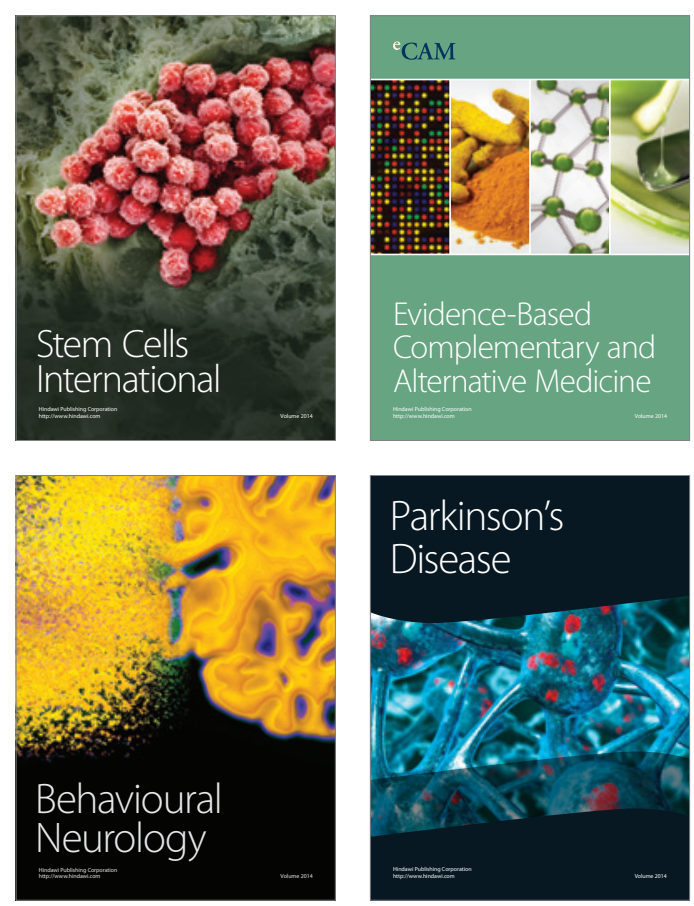

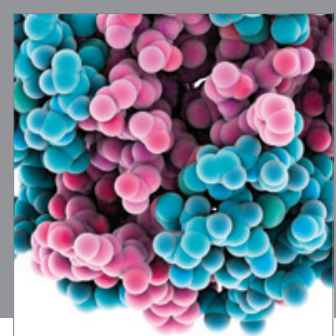

Journal of
Diabetes Research

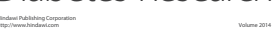

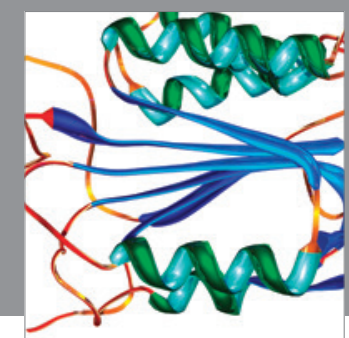

Disease Markers
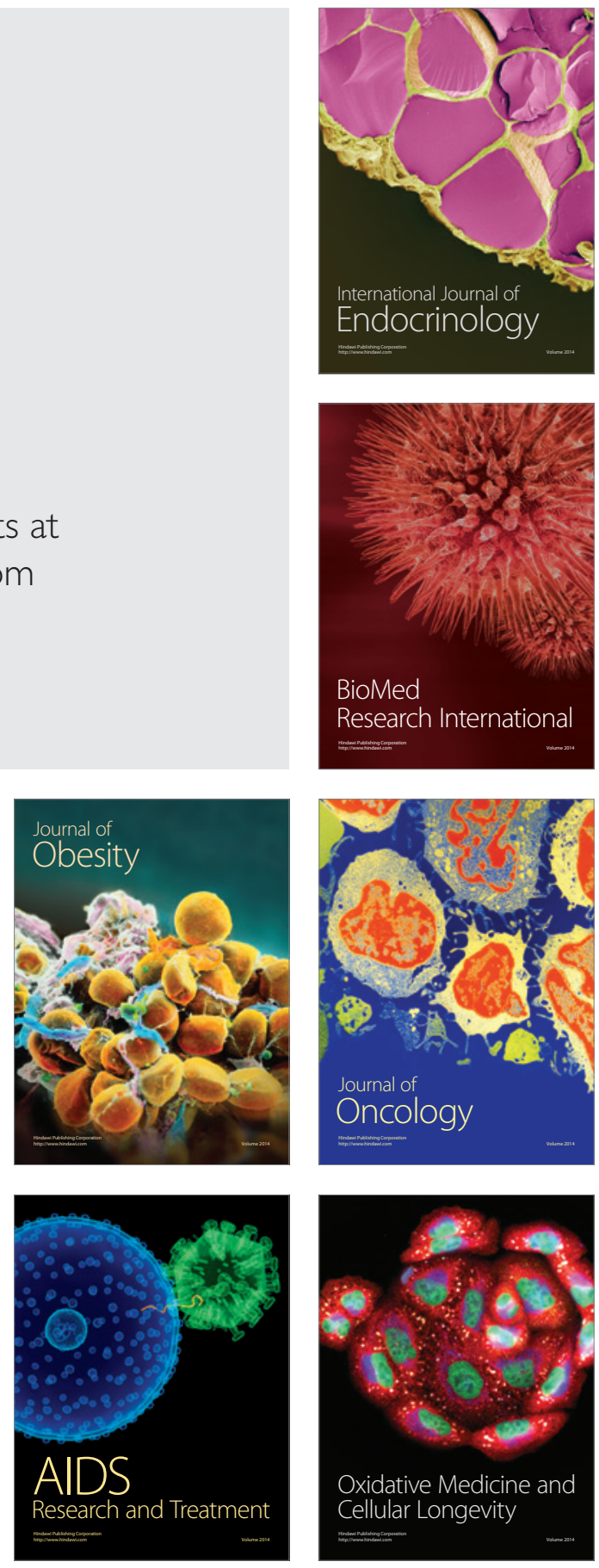